Review

\title{
A review on the sustainability of constructed wetlands for wastewater treatment: Design and operation
}

\author{
Haiming $\mathrm{Wu}^{\mathrm{a}, \mathrm{b}}$, Jian Zhang ${ }^{\mathrm{b}, *}$, Huu Hao $\mathrm{Ngo}^{\mathrm{c}}$, Wenshan Guo ${ }^{\mathrm{c}}$, Zhen Hu ${ }^{\mathrm{b}}$, Shuang Liang ${ }^{\mathrm{b}}$, Jinlin Fan ${ }^{\mathrm{d}}$, \\ Hai Liu ${ }^{\mathrm{b}}$ \\ ${ }^{a}$ College of Resources and Environment, Northwest A E F University, Yangling, Shaanxi 712100, China \\ ${ }^{\mathrm{b}}$ Shandong Key Laboratory of Water Pollution Control and Resource Reuse, School of Environmental Science E' Engineering, Shandong University, Jinan 250100, PR China \\ ${ }^{\mathrm{c} S}$ Shool of Civil and Environmental Engineering, University of Technology, Sydney, Broadway, NSW 2007, Australia \\ ${ }^{\mathrm{d}}$ National Engineering Laboratory of Coal-Fired Pollutants Emission Reduction, Shandong University, Jinan 250061, PR China
}

\section{H I G H L I G H T S}

- Sustainable operation and successful application is critical to CWs.

- We review the application of CWs as a green technology.

- We summarize the key design parameters for the sustainable operation of CWs.

- Future research is given on improving the stability and sustainability of CWs.

\section{A R T I C L E I N F O}

\section{Article history:}

Received 23 September 2014

Received in revised form 11 October 2014

Accepted 13 October 2014

Available online 25 October 2014

\section{Keywords:}

Constructed wetland

Wastewater treatment

Wetland plants

Pollutant removal

\begin{abstract}
A B S T R A C T
Constructed wetlands (CWs) have been used as a green technology to treat various wastewaters for several decades. CWs offer a land-intensive, low-energy, and less-operational-requirements alternative to conventional treatment systems, especially for small communities and remote locations. However, the sustainable operation and successful application of these systems remains a challenge. Hence, this paper aims to provide and inspire sustainable solutions for the performance and application of CWs by giving a comprehensive review of CWs' application and the recent development on their sustainable design and operation for wastewater treatment. Firstly, a brief summary on the definition, classification and application of current CWs was presented. The design parameters and operational conditions of CWs including plant species, substrate types, water depth, hydraulic load, hydraulic retention time and feeding mode related to the sustainable operation for wastewater treatments were then discussed. Lastly, future research on improving the stability and sustainability of CWs were highlighted.
\end{abstract}

(c) 2014 Elsevier Ltd. All rights reserved.

\section{Introduction}

At present, there are growing issues of water environment including water shortage, water pollution and degradation of water resources worldwide. Moreover, the situation is becoming more serious due to the combined effects of worsening environmentally-unfriendly activity and large population especially in developing countries (Vymazal, 2011; Wu et al., 2014). Historically, traditional centralized sewage treatment systems have been used successfully for water pollution control in most countries ( $\mathrm{Li}$ et al., 2014). However, these wastewater treatment technologies such as activated sludge process, membrane bioreactors and mem-

\footnotetext{
* Corresponding author.

E-mail address: zhangjian00@sdu.edu.cn (J. Zhang).
}

brane separation are rather expensive and not entirely feasible for widespread application in rural areas (Chen et al., 2014b). Furthermore, they are limited and insufficient when facing ever more stringent water and wastewater treatment standards (Wu et al., 2013a). Thus, selecting low-cost and efficient alternative technologies for wastewater treatment is significant especially in developing regions. For this purpose, constructed wetland (CWs), as a reasonable option for treating wastewater, are attracting great concern owing to lower cost, less operation and maintenance requirements (Rai et al., 2013).

CWs, a green treatment technology by simulating natural wetlands, has been widely used to treat various kinds of wastewater such as domestic sewage, agricultural wastewater, industrial effluent, mine drainage, landfill leachate, storm water, polluted river water, and urban runoff in the last few decades (Yalcuk and 
Ugurlu, 2009; Harrington and Scholz, 2010; Saeed and Sun, 2012, 2013; Badhe et al., 2014). Currently, numerous studies have focused on the design, development, and performance of CWs, and it was also reported that CWs could be efficient for removing various pollutants (organic matter, nutrients, trace elements, pharmaceutical contaminants, pathogens, etc.) from wastewater (Cui et al., 2010; Saeed and Sun, 2012).

However, long-term effective treatment performance in CWs and the sustainable operation remain a challenge. On one hand, plant species and media types are crucial influencing factors to the removal performance in CWs as they are considered to be the main biological component of CWs and change directly or indirectly the primary removal processes of pollutant over time (Arias et al., 2001; Li et al., 2008). On the other hand, the treatment performance of CWs is critically dependent on the optimal operating parameters (water depth, hydraulic retention time and load, feeding mode and design of setups, etc.) which could result in variations in removal efficiency of contaminants among different studies (Kadlec and Wallace, 2009; Wu et al., 2014). Additionally, a variety of pollutant removal of processes (e.g., sedimentation, filtration, precipitation, volatilization, adsorption, plant uptake, and various microbial processes) are generally directly and/or indirectly influenced by the different internal and external environment conditions such as temperatures, availability of dissolved oxygen and organic carbon source, operation strategies, $\mathrm{pH}$ and redox conditions in CWs (Calheiros et al., 2009; Chen et al., 2011; Saeed and Sun, 2012; Meng et al., 2014).

While much advancement has been made in the contaminant removal processes in CWs over the years, there is still a gap in the understanding of these systems that is limited to achieve sustained levels of water quality improvement. Meanwhile the indepth knowledge published in international journals and books on optimizing the treatment performance has increased dramatically in recent years. Therefore, it is necessary to review and discuss the recent development and knowledge on the sustainability of CW treatment technology. The objective of this paper is to categorize a great variety of CW treatments and provide an overall review on the application of CWs for wastewater treatment in recent years. This paper also reviews the developments in CWs considering plants and substrates selecting and operational parameters optimizing for the sustainability of wastewater treatments.
Moreover, future research considerations for improving the sustainability of CWs are highlighted.

\section{Constructed wetlands}

\subsection{Definition and classification}

Constructed wetlands are engineered wetlands which are designed and constructed to mimic natural wetland systems for treating wastewater. These systems, mainly comprised of vegetation, substrates, soils, microorganisms and water, utilize complex processes involving physical, chemical, and biological mechanisms to remove various contaminants or improve the water quality (Vymazal, 2011; Saeed and Sun, 2012).

A simple scheme for various types of CWs is shown in Fig. 1. As can be seen in Fig. 1, constructed wetlands for wastewater treatment are typically classified into two types according to the wetland hydrology: free water surface (FWS) CWs and subsurface flow (SSF) CWs (Saeed and Sun, 2012). FWS systems are similar to natural wetlands, with shallow flow of wastewater over saturated substrate. In SSF systems, wastewater flows horizontally or vertically through the substrate which supports the growth of plants, and based on the flow direction, SSF CWs could be further divided into vertical flow (VF) and horizontal flow (HF) CWs. A combination of various wetland systems, known as hybrid CWs was also introduced for the treatment of wastewater, and this design generally consisted of two stages of several parallel CWs in series, such as VF-HF CWs, HF-VF CWs, HF-FWS CWs and FWS-HF CWs (Vymazal, 2013a). In addition, the multi-stage CWs that were comprised of more than three stages CWs were used (Kadlec and Wallace, 2009). In recent years, to intensify removal processes of CWs, enhanced CWs such as artificial aerated CWs, baffled flow CWs, hybrid towery CWs, step feeding CWs and circular flow corridor CWs have been proposed to enhance the performance of systems for wastewater treatment (Wu et al., 2014).

\subsection{Cost-benefit analysis of CWs for wastewater treatment}

Based on the concept of sustainable development defined at Brundtland Commission, cost-benefit analysis has been considered

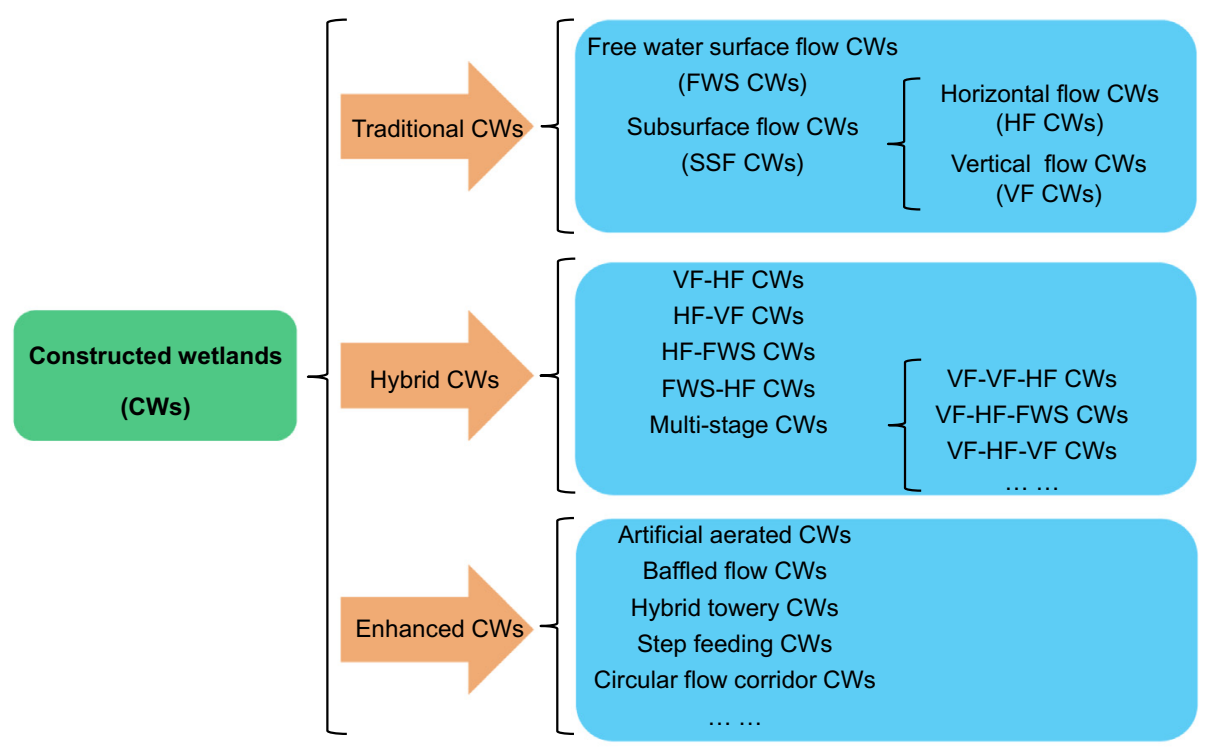

Fig. 1. The classification of CWs used in wastewater treatments. 
as adequate evaluation procedure for sustainable development activities. For the sustainability of a typical CW, cost-benefit analysis mainly involves land acquisition, investment and operation costs, energy consumption, ecological benefits, etc. A series of previous studies indicate that CWs have an apparent advantage in construction and operation costs in comparison with conventional wastewater treatment plants (WWTP) (Zhang et al., 2012; Wu et al., 2014). Similarly, energy consumption for CWs is far less than that of conventional WWTP. However, land requirements for CWs may be the most limiting factor for their broader application, especially in some regions, where land resources are scarce and population density is high. In addition, in order to achieve higher removal performance, those innovations such as artificial aeration will increase the lifecycle cost of CWs (Wu et al., 2014).

\subsection{Application of CWs for wastewater treatment}

The first attempt aimed at the possibility of CWs for wastewater treatment was made by Käthe Seidel in Germany in the early 1950s, and then the experiments on CWs were carried out and applied for wastewater treatments successively in the 1960s and 1970s. At the early stage, the application of CWs was mainly used for treating traditional domestic and municipal wastewater. At present the application of CWs has been significantly expanded to purify agricultural effluents, industrial effluents, mine drainage, landfill leachates, polluted river and lake waters, and urban and highway runoff, and has also been developed in various climate conditions such as warm and humid climate, arid and cold climate, tropical climate worldwide (Wu et al., 2014). Since the first fullscale CWs were built during the late 1960s, there are now more than 50,000 CWs in Europe and more than 10,000 CWs in North America (Kadlec and Wallace, 2009; Vymazal, 2011; Yan and Xu, 2014). In addition, CWs are a promising alternative for wastewater treatment in developing countries, and especially in China, thousands of CWs have been applied as wastewater treatment facilities (Chen et al., 2011).

Between FWS CWs and SSF CWs, FWS CWs are more efficient in the removal of organics and suspended solids, compared with nitrogen and phosphorus removal (Kadlec and Wallace, 2009). However, their treatment performance and sustainable application are usually restricted in the colder climate or after the plant decay (Vymazal, 2011). As compared to FWS CWs, SSF CWs are very effective in removal of organics, suspended solids, microbial pollution, and heavy metals, and they are less cold sensitive, and easier to insulate for winter operation. However, removal of nitrogen in this type of CWs depends on availability of oxygen and carbon source as a consequence of permanent water logged conditions, in addition, unless special media with high sorption capacity are used, low phosphorus removal is usually obtained (Babatunde et al., 2010). Considering the life span of CWs, owing to substrate clogging, SSF CWs may have significantly shorter life span than FWS CWs which could operate more than 10 years.

\section{Sustainable design and operation in constructed wetlands}

The criteria for CW design and operation include site selection, plant selection, substrate selection, wastewater type, plant material selection, hydraulic loading rate (HLR), hydraulic retention time (HRT), water depth, operation mood and maintenance procedures (Akratos et al., 2009; Kadlec and Wallace, 2009). Particularly, the factors such as plant selection, substrate selection, water depth, hydraulic loading rate (HLR), hydraulic retention time (HRT), and feeding mood may be crucial to establish a viable CW system and achieve the sustainable treatment performance.

\subsection{Plant selection in constructed wetlands}

Wetland plants which have several properties related to the treatment process could play a strategic role in CWs, and are considered to be the essential component of the design of CW treatments. However, only a few plant species have been widely used in constructed wetlands (Vymazal, 2013b). Selecting plants used in CWs should therefore be the focus of the current research on sustainable design of CWs (Vymazal, 2011). For the selection of plants, tolerance of waterlogged-anoxic and hyper-eutrophic conditions and capacity of pollutant absorption are recommended besides adaption to extreme climates.

\subsubsection{Plants used in constructed wetlands}

Macrophytes frequently used in CW treatments include emergent plants, submerged plants, floating leaved plants and freefloating plants. Although more than 150 macrophyte species have been used in CWs globally, only a limited number of these plant species are very often planted in CWs in reality (Vymazal, 2013b). The most common used emergent species are Phragmites spp. (Poaceae), Typha spp. (Typhaceae), Scirpus spp. (Cyperaceae), Iris spp. (Iridaceae), Juncus spp. (Juncaceae) and Eleocharis spp. (Spikerush). The most frequently used submerged plants are Hydrilla verticillata, Ceratophyllum demersum, Vallisneria natans, Myriophyllum verticillatum and Potamogeton crispus. The floating leaved plants are mainly Nymphaea tetragona, Nymphoides peltata, Trapa bispinosa and Marsilea quadrifolia. The free-floating plants are Eichhornia crassipes, Salvinia natans, Hydrocharis dubia and Lemna minor.

Among the above-mentioned macrophytes, emergent plants are the main vegetation in FWS and SSF CWs designed for wastewater treatments. Vymazal (2013b) surveyed emergent plants used in FWS CWs, and revealed that Phragmites australis is the most frequent species in Europe and Asia, Typha latifolia in North America, Cyperus papyrus in Africa, P. australis and Typha domingensis in Central/South Americas and Scirpus validus in Oceania. Similarly, a review of plants used in SSF CWs by Vymazal (2011) showed that by far the most frequently used plant around the globe is $P$. australis which has been particularly used throughout Europe, Canada, Australia and most parts of Asia and Africa. Typha (e.g., latifolia, domingensis, orientalis and glauca) spp. are the second most commonly used plants for SSF CWs, and they are most common in North America, Australia, Africa and East Asia. Scirpus (e.g., lacustris, validus, californicus and acutus) spp. are other commonly used plant species that are mostly used in North America, Australia and New Zealand. Juncus effusus and Eleocharis sp. may be mainly applied in Asia, Europe and North America (Vymazal, 2011). Moreover, some ornamental species (such as Iris pseudacorus) are especially used for CWs in the tropic and subtropic countries (Yan and $\mathrm{Xu}, 2014)$.

\subsubsection{Plant tolerance to wastewater}

Wetland plants would probably suffer from environmental stresses when CW treatments are used to remove various pollutants. Surrency (1993) pointed out that the extreme conditions of wastewater might exceed the tolerance of plants and limit both plant survivorship and treatment potential. In particular, when facing high loads of wastewaters or treating the wastewater containing toxic pollutants, CW treatments could hardly operate sustainably owing to decreasing of plant survivorship (Surrency, 1993). Environmental stresses could also cause direct damage to wetland plants, for example, eutrophication would inhibit plant growth and even cause disappearance of plants. Xu et al. (2010) also indicated that excessive amounts of ammonia will damage the physiology of plants and cause reduction in nutrient uptake of plants. External ammonia can cause chlorosis in leaves, suppres- 
sion of growth, lowering of root, and yield depressions in visual symptoms as well as trigger oxidative stress expressed through the enhancement of catalase and peroxidase (Xu et al., 2010).

In view of above facts, a number of studies have been done in evaluating the ability of tolerance to contaminant levels of various wastewaters. Surrency (1993) noted that T. latifolia was stressed by ammonia concentrations that averaged $160-170 \mathrm{mg} / \mathrm{L}$, while $S$. validus tolerated the extreme conditions. Hill et al. (1997) exposed five wetland plant species to ammonia concentrations between 20.5 and $82.4 \mathrm{mg} / \mathrm{L}$ in a field-scale experiment, and showed that only Scirpus acutus was negatively affected in this concentration range. Additionally, Li et al. (2011b) assessed the effect of increased ammonia concentration (up to $400 \mathrm{mg} / \mathrm{L}$ ) on three wetland plants and indicated that there are great differences in ammonia tolerance among these species, and Zornia latifolia had the highest ammonia tolerance. Similarly, Xu et al. (2010) studied the physiological responses of $P$. australis to wastewater with different chemical oxygen demand, and found that high COD levels ( $\geqslant 200 \mathrm{mg} / \mathrm{L}$ ) could disrupt the normal metabolism of the plant. High COD levels (COD $\geqslant 400 \mathrm{mg} / \mathrm{L}$ ) caused evident physiological changes in P. australis (Xu et al., 2010). Other studies indicated that Arundo donax and Sarcocornia fruticosa have a potential to treat high salinity wastewaters (up to $6.6 \mathrm{~g} \mathrm{Cl} / \mathrm{L}$ ), and to be very effective in removing organics, nitrogen and phosphorus (Calheiros et al., 2012). Chen et al. (2014a) found Typha angustata could survive in high concentrations of $\mathrm{Cr}$ (VI) solution up to $30 \mathrm{mg} / \mathrm{L}$ for 20 days and had an excellent accumulation ability. Furthermore, a study of the potential effect of antibiotics (at concentrations of $0-1000 \mathrm{~g} / \mathrm{L}$ ) on wetland plants showed that $P$. australis could both tolerate and remove antibiotics concentrations typically found in wastewater (Liu et al., 2013). Thus, such assessments are not only useful for understanding of the tolerance of wetland plants, but also provide the opportunity to select the most tolerant plant species in $\mathrm{CW}$ wastewater treatments.

\subsubsection{Capacity of plants in pollutants removal}

Wetland plant has been reported to be one of the main factors influencing water quality in wetlands. As the main biological component of CWs, plants act as intermedium for purification reactions by enhancing a variety of removal processes and directly utilizing nitrogen, phosphorous and other nutrients (Ong et al., 2010; Liu et al., 2011; Ko et al., 2011). In addition, they can accumulate toxic elements, such as heavy metals and antibiotics in wastewaters (Liu et al., 2013). Thus, numerous studies were performed on the uptake capacity of plants in CWs. Also the net uptake capacity of four emergent wetland plants was $6.50-26.57 \mathrm{~g} \mathrm{~N} / \mathrm{m}^{2}$ and $0.27-1.48 \mathrm{~g} \mathrm{P} / \mathrm{m}^{2}$ in CWs treating polluted river water (Wu et al., $2013 a, b)$. The capacity of uptake by plants may differ according to the system configurations, retention times, loading rates, wastewater types and climatic conditions (Saeed and Sun, 2012). The contribution of plants in terms of nitrogen and phosphorus removals has been considered to be high, accounting for $15-80 \% \mathrm{~N}$ and 24-80\% P (Greenway and Woolley, 2001). However, several authors found that it was lower and within the range $14.29-51.89 \%$ of the total nitrogen removal and $10.76-34.17 \%$ of the total phosphorus removal, respectively (Wu et al., 2013a,b).

In the case of emerging contaminant removal by CWs, for example, it was observed that wetland plants actively participated in the removal of carbamazepine, sulfonamides and trimethoprim when used in CW wastewater treatments (Dordio et al., 2011; Dan et al., 2013). The removal of carbamazepine from nutrient solutions by the plants reached values of $56-82 \%$ of the initial contents (from 0.5 to $2.0 \mathrm{mg} / \mathrm{L}$ ). For heavy metal removal, Ha et al. (2011) evaluated the accumulating capability of Eleocharis acicularis in different concentrations of $\mathrm{In}, \mathrm{Ag}, \mathrm{Pb}, \mathrm{Cu}, \mathrm{Cd}$, and $\mathrm{Zn}$, and the results showed that $E$. acicularis had the excellent ability to accumulate metals from water. In addition, Yadav et al. (2012) pointed out that heavy metal bioconcentration varied in different plants species, and below ground biomass removed more metal than above ground biomass.

\subsection{Substrate selection in constructed wetlands}

The substrate is the critical design parameter in CWs and SSF CWs in particular, because it can provide a suitable growing medium for plant and also allow successful movement of wastewater (Kadlec and Wallace, 2009). Moreover, substrate sorption may play the most important role in absorbing various pollutants such as phosphorus (Ju et al., 2014). Selection of suitable substrates to use in CWs for industrial wastewater treatment is an important issue.

\subsubsection{Substrates used for constructed wetlands}

The selection of substrates is determined in terms of the hydraulic permeability and the capacity of absorbing pollutants. Poor hydraulic conductivity would result in clogging of systems, severely decreasing the effectiveness of the system, and low adsorption by substrates could also affect the long-term removal performance of CWs (Wang et al., 2010). As shown in Table 1, several studies were carried out on selecting wetland substrates especially for sustainable phosphorus removal from wastewater, and the frequently used substrates mainly include natural material, artificial media and industrial by-product, such as gravel, sand, clay, calcite, marble, vermiculite, slag, fly ash, bentonite, dolomite, limestone, shell, zeolite, wollastonite, activated carbon, light weight aggregates (Albuquerque et al., 2009; Saeed and Sun, 2012; Chong et al., 2013; Yan and Xu, 2014). Results from these studies also suggest that substrates such as sand, gravel, and rock are the poor candidate for long-term phosphorus storage, but by contrast, artificial and industrial products with high hydraulic

Table 1

Substrates commonly selected for CW wastewater treatment.

\begin{tabular}{|c|c|}
\hline Type of substrates & Source \\
\hline $\begin{array}{l}\text { Natural material } \\
\text { Sand } \\
\text { Gravel } \\
\text { Clay } \\
\text { Calcite } \\
\text { Marble } \\
\text { Vermiculite } \\
\text { Bentonite } \\
\text { Dolomite } \\
\text { Limestone } \\
\text { Shell } \\
\text { Shale } \\
\text { Peat } \\
\text { Wollastonite } \\
\text { Maerl } \\
\text { Zeolite }\end{array}$ & $\begin{array}{l}\text { Saeed and Sun (2013) } \\
\text { Calheiros et al. (2008) } \\
\text { Calheiros et al. (2008) } \\
\text { Ann et al. (1999) } \\
\text { Arias et al. (2001) } \\
\text { Arias et al. (2001) } \\
\text { Xu et al. (2006) } \\
\text { Ann et al. (1999) } \\
\text { Tao and Wang (2009) } \\
\text { Seo et al. (2005) } \\
\text { Saeed and Sun (2012) } \\
\text { Saeed and Sun (2012) } \\
\text { Brooks et al. (2000) } \\
\text { Saeed and Sun (2012) } \\
\text { Bruch et al. (2011) }\end{array}$ \\
\hline $\begin{array}{l}\text { Industrial by-product } \\
\text { Slag } \\
\text { Fly ash } \\
\text { Coal cinder } \\
\text { Alum sludge } \\
\text { Hollow brick crumbs } \\
\text { Moleanos limestone } \\
\text { Wollastonite tailings } \\
\text { Oil palm shell }\end{array}$ & $\begin{array}{l}\text { Cui et al. (2010) } \\
\text { Xu et al. (2006) } \\
\text { Ren et al. (2007) } \\
\text { Babatunde et al. (2010) } \\
\text { Ren et al. (2007) } \\
\text { Mateus et al. (2012) } \\
\text { Hill et al. (1997) } \\
\text { Chong et al. (2013) }\end{array}$ \\
\hline $\begin{array}{l}\text { Artificial products } \\
\text { Activated carbon } \\
\text { Light weight aggregates } \\
\text { Compost } \\
\text { Calcium silicate hydrate } \\
\text { Ceramsite }\end{array}$ & $\begin{array}{l}\text { Ren et al. (2007) } \\
\text { Saeed and Sun (2012) } \\
\text { Saeed and Sun (2012) } \\
\text { Li et al. (2011a) } \\
\text { Li et al. (2011a) }\end{array}$ \\
\hline
\end{tabular}


conductivity and phosphorus sorption capacity could be alternative substrates in CWs. Other studies also provided some information on substrate selection in order to optimize the removal of nitrogen and organics, and the substrates such as alum sludge, peat, maerl, compost and rice husk are introduced (Babatunde et al., 2010; Saeed and Sun, 2012). Moreover, a mixture of substrates (sand and dolomite) was applied in CWs in removal of phosphates (Prochaska and Zouboulis, 2006), and the mixed (substrate gravel, vermiculite, ceramsite and calcium silicate hydrate) was also used in CWs for treating surface water with low nutrients concentration (Li et al., 2011a). These mixed substrates not only have reactive surfaces for microbial attachment, but also could provide a high hydraulic conductivity to avoid short-circuiting in CWs.

\subsubsection{Sorption capacity of substrates}

Substrates can remove pollutants from wastewater by exchange, adsorption, precipitation and complexation. The adsorption capacities of substrates vary each other and their capacity of sorption may depend primarily on the contents of the substrate, moreover, it could be influenced by the hydraulic and pollutant loading (Lai and Lamb, 2009). The previously studies by Arias et al. (2001), evaluating the phosphorus removal capacities of 13 Danish sands and their physico-chemical characteristics, indicated that the most important characteristic of sands determining their sorption phosphorus capacity was their Ca-content. Moreover, the phosphorus sorption capacity of sands would be used up after only a few months in full scale systems (Arias et al., 2001). Xu et al. (2006) studied the phosphorus sorption capacity of nine substrates, and showed that sorption capacity of sands varied between 0.13 and $0.29 \mathrm{~g} / \mathrm{kg}$. Similarly, the adsorption capacity of different substrates on ammonium removal in CWs has been investigated by Huang et al. (2012), and their results showed that the calculated maximum ammonium adsorption of zeolite $(11.6 \mathrm{~g} / \mathrm{kg})$ was significantly higher than that of volcanic rock $(0.21 \mathrm{~g} / \mathrm{kg})$. Furthermore, other experiments evaluated the adsorption capacity of a mixture of different substrates used in CWs. The phosphorus accumulation of a mixture of river sand and dolomite $(10: 1, w / w)$ substrates in the VF CWs tested by Prochaska and Zouboulis (2006) was found to be in the range of $6.5-18 \%$, and the estimated maximum adsorption capacity of the sand and dolomite mixture was $124 \mathrm{mg} \mathrm{P} / \mathrm{kg}$. Ren et al. (2007) also analyzed the adsorbing capacity of four kinds of substrates (fly ash, hollow brick crumbs, coal cinder and activated carbon pellets) used in CWs for treating domestic wastewater, and the static and dynamic experiments demonstrated that the adsorbing capacity of combined substrates was higher than that of single substrate. Lai and Lamb (2009) investigated the potential phosphorus removal of using a mixture of fishpond bund material, decomposed granite and river sand as substrate in the CW receiving influent stormwater, and the theoretical capacity for phosphorus adsorption was determined to be $478-858 \mathrm{mg} / \mathrm{kg}$ based on batch incubation experiments. In addition, increasing the proportion of decomposed granite in the substrate mix may enhance the phosphorus sorption capacity considerably, since there are abundant amorphous $\mathrm{Fe}$ and $\mathrm{Al}$ in the decomposed granite (Lai and Lamb, 2009).

\subsection{Optimization of design and operation}

\subsubsection{Water depth}

Water depth is a crucial factor in determining which plant types will become established, and it also influences the biochemical reactions responsible for removing contaminants by affecting the redox status and dissolved oxygen level in CWs (Song et al., 2009). Dwire et al. (2006) examined relations between water depth and plant species distribution in two riparian meadows in north- east Oregon, USA. Their results indicated that species richness such as wetland sedges was strongly related to water-table depth. Furthermore, studies of García et al. (2004) by comparing $0.27 \mathrm{~m}$ deep wetland beds with $0.5 \mathrm{~m}$ deep showed that differences occur in the transformations of pollutants within systems of different depths. Similarly, García et al. (2005) evaluated the effect of water depth on the removal of selected contaminants in HF CWs over a period of 3 years. The results indicated that beds with a water depth of $0.27 \mathrm{~m}$ removed better chemical oxygen demand, biochemical oxygen demand, ammonia and dissolved reactive phosphorus. In addition, experiments to investigate the effect of water depth on organic matter removal efficiency in HF CWs carried out by Aguirre et al. (2005) concluded that the relative contribution of different metabolic pathways varied with water depth.

\subsubsection{Hydraulic load and retention time}

Hydrology is one of the primary factors in controlling wetland functions, and flow rate should also be regulated to achieve a satisfactory treatment performance (Lee et al., 2009). The optimal design of hydraulic loading rate (HLR) and hydraulic retention time (HRT) plays an important role in the removal efficiency of CWs. Greater HLR promotes quicker passage of wastewater through the media, thus reducing the optimum contact time. On the contrary, an appropriate microbial community may be established in CWs and have adequate contact time to remove contaminants at a longer HRT (Saeed and Sun, 2012; Yan and Xu, 2014). Huang et al. (2000) reported that ammonium and TN concentrations in treated effluent decreased dramatically with increasing HRT in CWs treating domestic wastewater. Similarly, Toet et al. (2005) found positive nitrogen removal in CWs with a HRT of 0.8 days comparing with the results with 0.3 days residence time. A low HRT in CWs may be associated with incomplete denitrification of wastewater, and it is reported that nitrogen removal requires a longer HRT compared with that required for removal of organics (Lee et al., 2009). Furthermore, the effect of HRT may differ between CWs depending on the dominant plant species and temperature, as those factors can affect the hydraulic efficiency of wetlands. Accordingly, in a long-term experiment Cui et al. (2010) observed a minor decrease of ammonium and TN removal from domestic wastewater in VF CWs, when HLR changed from 7 to $21 \mathrm{~cm} / \mathrm{d}$. Accordingly, mean ammonium removal decreased from $65 \%$ to $60 \%$, whereas TN reduced from $30 \%$ to $20 \%$. However, Stefanakis and Tsihrintzis (2012) reported a long term evaluation of fully matured VF CWs for treating synthetic wastewater, and showed that the wetland systems achieved higher nitrogen and organics removal as the HLR increased. Avila et al. (2014) also studied the feasibility of hybrid CW systems used for removing emerging organic contaminants, and demonstrated that the removal efficiency for most compounds decreased as the HLR increased.

\subsubsection{Feeding mode of influent}

The feeding mode of influent has been shown to be another important design parameter (Zhang et al., 2012). The difference of feeding mode (such as continuous, batch and intermittent) may influence the oxidation-reduction conditions and oxygen transfer and diffusion in wetland systems and, hence, modify the treatment efficiency. Various studies were conducted to evaluate the effect of influent feeding modes on the removal efficiency of $\mathrm{CW}$ treatments. In general, batch feeding mode can obtain the better performance than continuous operation by promoting more oxidized conditions. Zhang et al. (2012) investigated the influence of batch versus continuous flow on the removal efficiencies in tropical SSF CWs. They indicated that the wetlands with batch flow mode showed significantly higher ammonium removal efficiencies (95.2\%) compared with the continuously fed systems (80.4\%). However, there still exists uncertainty about whether batch operation 
improves removal efficiencies when compared to continuous feeding mode.

Intermittent feeding mode can be considered to enhance organics and nitrogen removal in CWs (Saeed and Sun, 2012). Caselles-Osorio and García (2007) evaluated the effect of continuous and intermittent feeding modes on contaminant removal efficiency in SSF CWs, and noted that intermittent feeding improved ammonium removal performances in wetland systems when compared with continuous feeding. However, sulfate removal was higher in the continuously fed systems compared with the intermittently fed systems. Jia et al. (2010) also studied the influences of intermittent operation and different length of drying time on removal efficiencies in VF CWs, and compared with continuous operation in wetland systems, the intermittent operation promoted a lower level of COD and TP removal. Furthermore, the intermittent operation greatly enhanced the ammonium removal efficiency (more than 90\%), which may be attributed to more oxidizing conditions in wetlands. Similarly, the impacts of continuous and intermittent feeding modes on nitrogen removal in FWS and SSF CWs were evaluated by Jia et al. (2011). Results showed that the intermittent feeding mode enhanced the ammonium removal effectively in SSF CWs without any significant effect for FWS CWs.

\section{Future considerations on the sustainability of CWs}

It has been widely recognized that CWs are a reliable treatment technology for various wastewaters after years of study and implementation. The current review indicates that advances in the design and operation of CWs have greatly increased contaminant removal efficiencies, and the sustainable application of this treatment system has also been improved. For example, the excellent performance in CWs for treating high strength wastewater or under cold climatic conditions can be achieved by suitable manipulation of the hydraulic design, mode of operation, the pollutant loading rate, and possibly by plants and substrates selection. In Table 2 recommendations on the design and operation of CWs for wastewater treatment are shown. However, given the increasingly strict water quality standards for wastewater treatments and water reuse worldwide, CWs still has some limitations, and further research and development work is necessary. In summary (Fig. 2):

(1) The review on plants and substrates selection indicates that wetland macrophytes and substrates are still critical for the sustainable pollutant removal from wastewater in CWs. It should be paid more attention to proper macrophyte species selection (i.e., large biomass production, rich supply of

Table 2

Recommendations on the design and operation of CWs for wastewater treatment.

\begin{tabular}{lll}
\hline Parameter & Design criteria & SSF CWs \\
\cline { 2 - 3 } & FWS CWs & $<2500$ \\
\hline Bed size $\left(\mathrm{m}^{2}\right)$ & Larger if available & $<3: 1$ \\
Length to width ratio & $3: 1-5: 1$ & $0.4-1.6$ \\
Water depth (m) & $0.3-0.5$ & $0.5-1$ \\
Hydraulic slope (\%) & $<0.5$ & $<0.5$ \\
Hydraulic loading rate (m/day) & $<0.1$ & $2-5$ \\
Hydraulic retention time (day) & $5-30$ & Natural media and industrial by-product preferred, porosity $0.3-0.5$, particle size $<20$ mm (50-200 mm for the \\
Media & inflow and outflow) & \\
Vegetation & Native species preferred, plant density 80\% coverage & \\
\hline
\end{tabular}

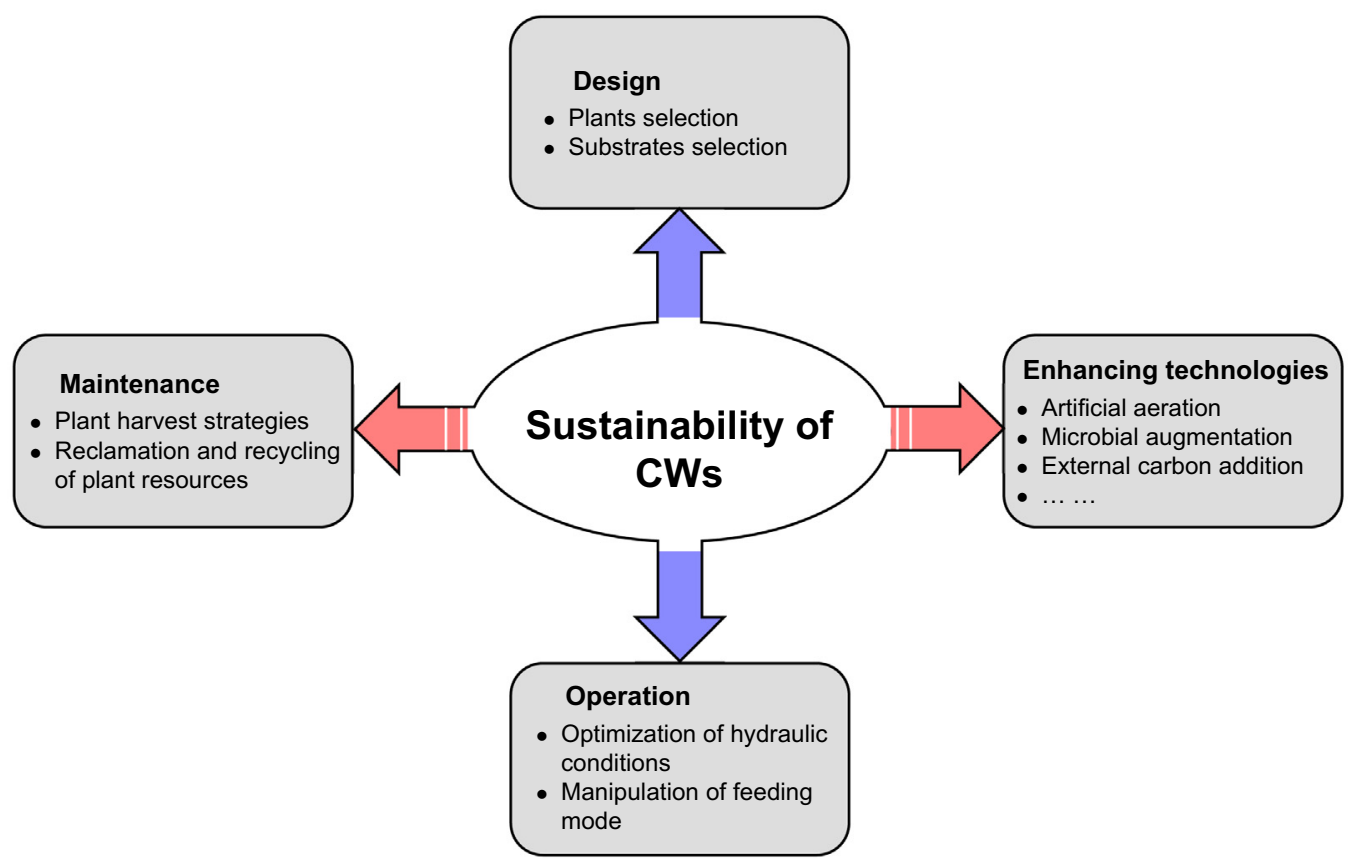

Fig. 2. Summary of current developments and future considerations for improving the sustainability of CWs. 
oxygen and carbon compounds, high uptake of pollutants especially emerging contaminants such as heavy metals and pharmaceuticals, tolerance of high pollutant loadings) applied in CWs in temperate and cold climates for wastewater treatment whilst an intensive evaluation of differences between species and season is also needed. In addition, some non-conventional wetland media (industrial byproduct, agricultural wastes, etc.) which has high sorption capacity and is beneficial to removal processes should be developed and used for CWs.

(2) The review on design and operating parameters shows that the optimal treatment performance is vitally dependent on environmental, hydraulic and operating conditions. Therefore, optimizing these conditions demands extensive investigation in future studies. Furthermore research of the key pathway and mechanism corresponding to higher pollutant removal should also be taken into consideration.

(3) Although the research and practical application in traditional CWs have been going on development, novel technologies and strategies for the enhancement of wastewater applied in CWs are critically required for sustainable water quality improvement in future studies. These technologies and strategies may include: artificial aeration, tidal operation, step feeding, external carbon addition, microbial augmentation, allocation of various plants, combination of various substrates, baffled flow CWs and hybrid CWs, etc.

(4) It is reported that nutrients and other pollutants assimilated by wetland plants could release into water when plants die and decay during the cold winter, which may results in a poor removal performance in CWs. Hence, research and development on appropriate plant harvest strategies, and reclamation and recycling of plant resources in CWs are essential.

\section{Conclusion}

This review based study illustrates that the factors for CW design and operation such as plant selection, substrate selection, water depth, loading rate, hydraulic retention time, and feeding mode are crucial to achieve the sustainable treatment performance. Considering the successful and sustainable application of full-scale CWs, future studies should focus on comprehensive evaluation of plants and substrates in field trials under real life conditions, optimization of environmental and operational parameters (e.g., influent loads and tidal operation), exploration of novel enhancement technologies (e.g., microbial augmentation) and maintenance strategies (e.g., plant harvest).

\section{Acknowledgements}

This work was supported by National Natural Science Foundation of China (21177075), Program for New Century Excellent Talents in University (NCET-10-0554) and Natural Science Foundation for Distinguished Young Scholars of shandong province (JQ201216).

\section{References}

Aguirre, P., Ojeda, E., García, J., Barragán, J., Mujeriego, R., 2005. Effect of water depth on the removal of organic matter in horizontal subsurface flow constructed wetlands. J. Environ. Sci. Health A 40, 1457-1466.

Akratos, C.S., Papaspyros, J.N., Tsihrintzis, V.A., 2009. Total nitrogen and ammonia removal prediction in horizontal subsurface flow constructed wetlands: use of artificial neural networks and development of a design equation. Bioresour. Technol. 100, 586-596.

Albuquerque, A., Oliveira, J., Semitela, S., Amaral, L., 2009. Influence of bed media characteristics on ammonia and nitrate removal in shallow horizontal subsurface flow constructed wetlands. Bioresour. Technol. 100, 6269-6277.
Ann, Y., Reddy, K.R., Delfino, J.J., 1999. Influence of chemical amendments on phosphorus immobilization in soils from a constructed wetland. Ecol. Eng. 14, $157-167$.

Arias, C.A., Del Bubba, M., Brix, H., 2001. Phosphorus removal by sands for use as media in subsurface flow constructed reed beds. Water Res. 35, 1159-1168.

Avila, C., Matamoros, V., Reyes-Contreras, C., Piña, B., Casado, M., Mita, L., Rivetti, C., Barata, C., García, J., Bayona, J.M., 2014. Attenuation of emerging organic contaminants in a hybrid constructed wetland system under different hydraulic loading rates and their associated toxicological effects in wastewater. Sci. Total Environ. 470-471, 1272-1280.

Babatunde, A.O., Zhao, Y.Q., Zhao, X.H., 2010. Alum sludge-based constructed wetland system for enhanced removal of P and OM from wastewater: concept, design and performance analysis. Bioresour. Technol. 101, 6576-6579.

Badhe, N., Saha, S., Biswas, R., Nandy, T., 2014. Role of algal biofilm in improving the performance of free surface, up-flow constructed wetland. Bioresour. Technol. 169, 596-604.

Brooks, A.S., Rozenwald, M.N., Geohring, L.D., Lion, L.W., Steenhuis, T.S., 2000 Phosphorus removal by wollastonite: a constructed wetland substrate. Ecol. Eng. 15, 121-132.

Bruch, I., Fritsche, J., Bänninger, D., Alewella, U., Sendelov, M., Hürlimann, H. Hasselbach, R., Alewell, C., 2011. Improving the treatment efficiency of constructed wetlands with zeolite-containing filter sands. Bioresour. Technol. 102, 937-941.

Calheiros, C.S., Rangel, A.O., Castro, P.M., 2008. Evaluation of different substrates to support the growth of Typha latifolia in constructed wetlands treating tannery wastewater over long-term operation. Bioresour. Technol. 99, 6866-6877.

Calheiros, C.S., Duque, A.F., Moura, A., Henriques, I.S., Correia, A., Rangel, A.O., Castro, P.M., 2009. Changes in the bacterial community structure in two-stage constructed wetlands with different plants for industrial wastewater treatment. Bioresour. Technol. 100, 3228-3235.

Calheiros, C.S., Quitério, P.V., Silva, G., Crispim, L.F., Brix, H., Moura, S.C., Castro, P.M., 2012. Use of constructed wetland systems with Arundo and Sarcocornia for polishing high salinity tannery wastewater. J. Environ. Manage. 95, 66-71.

Caselles-Osorio, A., García, J., 2007. Impact of different feeding strategies and plant presence on the performance of shallow horizontal subsurface-flow constructed wetlands. Sci. Total Environ. 378, 253-262.

Chen, Y., Wen, Y., Cheng, J., Xue, C.H., Yang, D.H., Zhou, Q., 2011. Effects of dissolved oxygen on extracellular enzymes activities and transformation of carbon sources from plant biomass: implications for denitrification in constructed wetlands. Bioresour. Technol. 102, 2433-2440.

Chen, Y., Hong, X., He, H., Luo, H., Qian, T., Li, R., Jiang, Hong., Yu, H., 2014a. Biosorption of $\mathrm{Cr}(\mathrm{VI})$ by Typha angustifolia: mechanism and responses to heavy metal stress. Bioresour. Technol. 160, 89-92.

Chen, Y., Wen, Y., Zhou, Q., Vymazal, J., 2014b. Effects of plant biomass on denitrifying genes in subsurface-flow constructed wetlands. Bioresour. Technol. 157, 341-345.

Chong, H.L., Chia, P.S., Ahmad, M.N., 2013. The adsorption of heavy metal by Bornean oil palm shell and its potential application as constructed wetland media. Bioresour. Technol. 130, 181-186.

Cui, L., Ouyang, Y., Lou, Q., Yang, F., Chen, Y., Zhu, W., Luo, S., 2010. Removal of nutrients from wastewater with Canna indica $\mathrm{L}$. under different vertical-flow constructed wetland conditions. Ecol. Eng. 36, 1083-1088.

Dan, A., Yang, Y., Dai, Y.N., Chen, C.X., Wang, S.Y., Tao, R., 2013. Removal and factors influencing removal of sulfonamides and trimethoprim from domestic sewage in constructed wetlands. Bioresour. Technol. 146, 363-370.

Dordio, A.V., Belo, M., Martins Teixeira, D., Palace Carvalho, A.J., Dias, C.M., Picó, Y., Pinto, A.P., 2011. Evaluation of carbamazepine uptake and metabolization by Typha spp., a plant with potential use in phytotreatment. Bioresour. Technol. 102, 7827-7834.

Dwire, K.A., Kauffman, J.B., Baham, J.E., 2006. Plant species distribution in relation to water-table depth and soil redox potential in montane riparian meadows. Wetlands 26, 131-146.

García, J., Aguirre, P., Mujeriego, R., Huang, Y., Ortiz, L., Bayona, J.M., 2004. Initial contaminant removal performance factors in horizontal flow reed beds used for treating urban wastewater. Water Res. 38, 1669-1678.

García, J., Aguirre, P., Barragán, J., Mujeriego, R., Matamoros, V., Bayona, J.M., 2005. Effect of key design parameters on the efficiency of horizontal subsurface flow constructed wetlands. Ecol. Eng. 25, 405-418.

Greenway, M., Woolley, A., 2001. Changes in plant biomass and nutrient removal over 3 years in a constructed wetland, Cairns, Australia. Water Sci. Technol. 44, 303-310.

Ha, N.T., Sakakibara, M., Sano, S., 2011. Accumulation of Indium and other heavy metals by Eleocharis acicularis: an option for phytoremediation and phytomining. Bioresour. Technol. 102, 2228-2234.

Harrington, C., Scholz, M., 2010. Assessment of pre-digested piggery wastewater treatment operations with surface flow integrated constructed wetland systems. Bioresour. Technol. 101, 7713-7723.

Hill, D.T., Payne, V.W.E., Rogers, J.W., Kown, S.R., 1997. Ammonia effects on the biomass production of five constructed wetland plant species. Bioresour Technol. 62, 109-113.

Huang, J., Reneau, R., Hageborn, C., 2000. Nitrogen removal in constructed wetlands employed to treat domestic wastewater. Water Res. 34, 2582-2588.

Huang, X., Liu, C., Wang, Z., Gao, C., Zhu, G., Liu, L., 2012. The effects of different substrates on ammonium removal in constructed wetlands: a comparison of their physicochemical characteristics and ammonium-oxidizing prokaryotic communities. CLEAN - Soil Air Water 1, 283-290. 
Jia, W., Zhang, J., Wu, J., Xie, H., Zhang, B., 2010. Effect of intermittent operation on contaminant removal and plant growth in vertical flow constructed wetlands: a microcosm experiment. Desalination 262, 202-208.

Jia, W.L., Zhang, J., Li, P.Z., Xie, H.J., Wu, J., Wang, J.H., 2011. Nitrous oxide emissions from surface flow and subsurface flow constructed wetland microcosms: effect of feeding strategies. Ecol. Eng. 37, 1815-1821.

Ju, X., Wu, S., Huang, X., Zhang, Y., Dong, R., 2014. How the novel integration of electrolysis in tidal flow constructed wetlands intensifies nutrient removal and odor control. Bioresour. Technol. 169, 605-613.

Kadlec, R.H., Wallace, S.D., 2009. Treatment Wetlands, second ed. CRC Press/Taylor \& Francis Group, Boca Raton, FL 33487-2742, USA.

Ko, C.H., Lee, T.M., Chang, F.C., Liao, S.P., 2011. The correlations between system treatment efficiencies and aboveground emergent macrophyte nutrient removal for the Hsin-Hai Bridge phase II constructed wetland. Bioresour. Technol. 102, 5431-5437.

Lai, D.Y., Lamb, K.C., 2009. Phosphorus sorption by sediments in a subtropical constructed wetland receiving stormwater runoff. Ecol. Eng. 35, 735-743.

Lee, C., Fletcher, T.D., Sun, G., 2009. Nitrogen removal in constructed wetland systems. Eng. Life Sci. 9, 11-22.

Li, J., Wen, Y., Zhou, Q., Xingjie, Z., Li, X., Yang, S., Lin, T., 2008. Influence of vegetation and substrate on the removal and transformation of dissolved organic matter in horizontal subsurface-flow constructed wetlands. Bioresour. Technol. 99, 49904996.

Li, C.J., Wan, M.H., Dong, Y., Men, Z.Y., Lin, Y., Wu de, Y., Kong, H.N., 2011a. Treating surface water with low nutrients concentration by mixed substrates constructed wetlands. J. Environ. Sci. Health A 46, 771-776.

Li, C., Zhang, B., Zhang, J., Wu, H., Xie, H., Xu, J., Qi, P., 2011b. Physiological responses of three plant species exposed to excess ammonia in constructed wetland. Desalin. Water Treat. 32, 271-276.

Li, Y., Zhu, G., Ng, W.J., Tan, S.K., 2014. A review on removing pharmaceutical contaminants from wastewater by constructed wetlands: design, performance and mechanism. Sci. Total Environ. 468-469, 908-932.

Liu, W.J., Zeng, F.X., Jiang, H., Yu, H.Q., 2011. Total recovery of nitrogen and phosphorus from three wetland plants by fast pyrolysis technology. Bioresour. Technol. 102, 3471-3479.

Liu, L., Liu, Y., Liu, C., Wang, Z., Dong, J., Zhu, G., Huang, X., 2013. Potential effect and accumulation of veterinary antibiotics in Phragmites australis under hydroponic conditions. Ecol. Eng. 53, 138-143.

Mateus, D.M.R., Vaz, M.M.N., Pinho, H.J.O., 2012. Fragmented limestone wastes as a constructed wetland substrate for phosphorus removal. Ecol. Eng. 41, 65-69.

Meng, P., Pei, H., Hu, W., Shao, Y., Li, Z., 2014. How to increase microbial degradation in constructed wetlands: influencing factors and improvement measures. Bioresour. Technol. 157, 316-326.

Ong, S.A., Uchiyama, K., Inadama, D., Ishida, Y., Yamagiwa, K., 2010. Performance evaluation of laboratory scale up-flow constructed wetlands with different designs and emergent plants. Bioresour. Technol. 101, 7239-7244.

Prochaska, C.A., Zouboulis, A.I., 2006. Removal of phosphates by pilot vertical-flow constructed wetlands using a mixture of sand and dolomite as substrate. Ecol Eng. 26, 293-303.

Rai, U.N., Tripathi, R.D., Singh, N.K., Upadhyay, A.K., Dwivedi, S., Shukla, M.K. Mallick, S., Singh, S.N., Nautiyal, C.S., 2013. Constructed wetland as an ecotechnological tool for pollution treatment for conservation of Ganga river. Bioresour. Technol. 148, 535-541.

Ren, Y., Zhang, B., Liu, Z., Wang, J., 2007. Optimization of four kinds of constructed wetlands substrate combination treating domestic sewage. Wuhan Univ. J. Nat. Sci. $12,1136-1142$

Saeed, T., Sun, G., 2012. A review on nitrogen and organics removal mechanisms in subsurface flow constructed wetlands: dependency on environmental parameters, operating conditions and supporting media. J. Environ. Manage. $112,429-448$.
Saeed, T., Sun, G., 2013. A lab-scale study of constructed wetlands with sugarcane bagasse and sand media for the treatment of textile wastewater. Bioresour. Technol. 128, 438-447.

Seo, D.C., Cho, J.S., Lee, H.J., Heo, J.S., 2005. Phosphorus retention capacity of filter media for estimating the longevity of constructed wetland. Water Res. 39, 2445-2457.

Song, H.L., Nakano, K., Taniguchi, T., Nomura, M., Nishimura, O., 2009. Estrogen removal from treated municipal effluent in small-scale constructed wetland with different depth. Bioresour. Technol. 100, 2945-2951.

Stefanakis, A.I., Tsihrintzis, V.A., 2012. Effects of loading, resting period, temperature, porous media, vegetation and aeration on performance of pilotscale vertical flow constructed wetlands. Chem. Eng. J. 181-182, 416-430.

Surrency, D., 1993. Evaluation of aquatic plants for constructed wetlands. In: Moshiri, G.A. (Ed.), Constructed Wetlands for Water Quality Improvement. Lewis Publishers, Boca Raton, FL, pp. 349-357.

Tao, W., Wang, J., 2009. Effects of vegetation, limestone and aeration on nitritation, anammox and denitrification in wetland treatment systems. Ecol. Eng. 35, 836842 .

Toet, S., Logtestijn, R.S.P.V., Kampf, R., Schreijer, M., Verhoeven, J.T.A., 2005. The effect of hydraulic retention time on the removal of pollutants from sewage treatment plant effluent in a surface-flow wetland system. Wetlands $25,375-$ 391.

Vymazal, J., 2011. Plants used in constructed wetlands with horizontal subsurface flow: a review. Hydrobiologia 674, 133-156.

Vymazal, J., 2013a. The use of hybrid constructed wetlands for wastewater treatment with special attention to nitrogen removal: a review of a recent development. Water Res. 47, 4795-4811.

Vymazal, J., 2013b. Emergent plants used in free water surface constructed wetlands: a review. Ecol. Eng. 61, 582-592.

Wang, R., Korboulewsky, N., Prudent, P., Domeizel, M., Rolando, C., Bonin, G., 2010 Feasibility of using an organic substrate in a wetland system treating sewage sludge: impact of plant species. Bioresour. Technol. 101, 51-57.

Wu, H., Zhang, J., Li, C., Fan, J., Zou, Y., 2013a. Mass balance study on phosphorus removal in constructed wetland microcosms treating polluted river water. CLEAN - Soil Air Water 41, 844-850.

Wu, H., Zhang, J., Wei, R., Liang, S., Li, C., Xie, H., 2013b. Nitrogen transformations and balance in constructed wetlands for slightly polluted river water treatment using different macrophytes. Environ. Sci. Pollut. Res. 20, 443-451.

Wu, S., Kuschk, P., Brix, H., Vymazal, J., Dong, R., 2014. Development of constructed wetlands in performance intensifications for wastewater treatment: a nitrogen and organic matter targeted review. Water Res. 57C, 40-55.

Xu, D., Xu, J., Wu, J., Muhammad, A., 2006. Studies on the phosphorus sorption capacity of substrates used in constructed wetland systems. Chemosphere 63, 344-352.

Xu, J., Zhang, J., Xie, H., Li, C., Bao, N., Zhang, C., Shi, Q., 2010. Physiological responses of Phragmites australis to wastewater with different chemical oxygen demands. Ecol. Eng. 36, 1341-1347.

Yadav, A.K., Abbassi, R., Kumar, N., Satya, S., Sreekrishnan, T.R., Mishra, B.K., 2012. The removal of heavy metals in wetland microcosms: effects of bed depth, plant species, and metal mobility. Chem. Eng. J. 211-212, 501-507.

Yalcuk, A., Ugurlu, A., 2009. Comparison of horizontal and vertical constructed wetland systems for landfill leachate treatment. Bioresour. Technol. 100, 2521 2526.

Yan, Y., Xu, J., 2014. Improving winter performance of constructed wetlands for wastewater treatment in Northern China: a review. Wetlands 34, 243-253.

Zhang, D.Q., Tan, S.K., Gersberg, R.M., Zhu, J., Sadreddini, S., Li, Y., 2012. Nutrient removal in tropical subsurface flow constructed wetlands under batch and continuous flow conditions. J. Environ. Manage. 96, 1-6. 